\title{
Structural characterization and ecological roles of a novel exopolysaccharide from the deep-sea psychrotolerant bacterium Pseudoalteromonas sp. SM9913 \\ Correspondence Yuzhong Zhang zhangyz@sdu.edu.cn \\ Received 10 October 2006 \\ Revised 19 December 2006 Accepted 24 January 2007

\author{
Guokui Oin, ${ }^{1}$ Lizhi Zhu, ${ }^{2}$ Xiulan Chen, ${ }^{1}$ Peng George Wang ${ }^{1,2}$ \\ and Yuzhong Zhang ${ }^{1}$ \\ 'State Key Lab of Microbial Technology, Marine Biotechnology Research Center, \\ Shandong University, Jinan, 250100, P. R. China \\ ${ }^{2}$ Department of Biochemistry, The Ohio State University, Columbus, OH 43210, USA
}

\begin{abstract}
Pseudoalteromonas sp. SM9913 is a psychrotolerant bacterium isolated from deep-sea sediment. The structural characterization and ecological roles of the exopolysaccharide (EPS) secreted by this strain were studied in this work. The yield of the EPS increased as the culture temperature decreased in the range $30-10^{\circ} \mathrm{C}$, and it reached $5.25 \mathrm{~g} \mathrm{I}^{-1}$ (dry weight) under optimal growth conditions $\left(15^{\circ} \mathrm{C}, 52 \mathrm{~h}\right.$ ). EPS fraction was purified and its structure was identified by the combination of NMR spectra, high-resolution mass spectrometry (HRMS) analysis and methylation analysis. The ratio of the sugar units, the acetyl group and the ethoxyl group was close to $4: 5: 1$. The major sugar unit of the EPS was 6-linked glucose (61.8\%); other sugar units present included terminal arabinofuranosyl (11.0\%) and glucopyranosyl (11.2\%) residues and a small amount of other sugar derivatives. Its structure was different from EPSs reported for other marine bacteria. Besides the structural elucidation of the EPS, its ecological roles were studied. This EPS could enhance the stability of the cold-adapted protease MCP-01 secreted by the same strain through preventing its autolysis. It could bind many metal ions, including $\mathrm{Fe}^{2+}, \mathrm{Zn}^{2+}, \mathrm{Cu}^{2+}, \mathrm{Co}^{2+}$. It was also a very good flocculating agent and could conglomerate colloidal and suspended particles. These results indicated that the EPS secreted by strain SM9913 might help this strain enrich the proteinaceous particles and the trace metals in the deep-sea environment, stabilize the secreted cold-adapted proteases and avoid its diffusion. This is believed to be the first report on the structure of the EPS secreted by a deep-sea psychrotolerant bacterium and its ecological roles. According to these results and other studies, a schematic diagram of the lifestyle of the deep-sea psychrotolerant strain SM9913 is suggested.
\end{abstract}

\section{INTRODUCTION}

The deep sea is a major component of the planet's biosphere and represents $75 \%$ of the total volume of the oceans. Current studies have focused on the extremophilic microorganisms isolated from deep-sea hydrothermal vents (Staley \& Gosink, 1999; Guezennec, 2002), and a variety of fascinating micro-organisms well adapted to these extreme environments have been investigated (Guezennec, 2003). Due to the attractive chemical and rheological properties of polysaccharides produced by these extremophilic micro-organisms, studies have been conducted to

Abbreviations: COSY, correlation spectroscopy; EPS, exopolysaccharide; HRMS, high-resolution mass spectrometry; HSOC, heteronuclear single quantum correlation.

Supplementary data are available with the online version of this paper. investigate their potential application in biotechnology, environmental protection, the food industry, and so on (Kirschner \& Woods, 2001; Colliec-Jouault et al., 2004). Although the structures of some exopolysaccharides (EPSs) from deep-sea hydrothermal vents have been reported (Rougeaux et al., 1999a, b; Cambon-Bonavita et al., 2002; Raguenes et al., 2003), there have been few reports on their ecological roles. The genome sequence of the deep-sea gammaproteobacterium Idiomarina loihiensis was reported and it was suggested that this species relies primarily on amino acids, rather than on carbohydrates, for carbon and energy (Hou et al., 2004). The versatile signal transduction system of I. loihiensis apparently aids its survival and growth, and initiates the synthesis and secretion of highly viscous EPS(s) for attachment to proteinaceous particles. It would appear that deep-sea EPSs could serve as enhancers for the survival of deep-sea bacteria in a fluctuating environment 
(Hou et al., 2004). However, this hypothesis has not yet been confirmed by any experimental results.

The deep-sea hydrothermal vents only represent a small and particular portion of the whole deep-sea environment. Most deep-sea environments are influenced by high pressure, low temperature and low nutrient concentration. Many kinds of deep-sea psychrotolerant bacteria live in the abyssal ecological community. Survival in these conditions requires a complex suite of morphological, physiological and metabolic adaptations. Therefore, the investigation and study of deep-sea psychrotolerant bacteria may reveal important ecological characteristics enabling the adaptation of bacteria to the constantly changing deep-sea ecosystem (Rademacher et al., 1988).

Psychrotolerant bacterium Pseudoalteromonas sp. SM9913 (its detailed characteristics are shown in Part I of the supplementary data available with the online version of this paper; the GenBank accession number of the $16 \mathrm{~S}$ rDNA of this strain is AY305857), a gammaproteobacterium, was screened from $1855 \mathrm{~m}$ deep-sea sediment. It secreted at least three different extracellular proteases, MCP-01, MCP-02 (Chen et al., 2003a; GenBank accession no. ABD14413.2 for MCP-01, EF029091 for MCP-02) and MCP-03 (unpublished results, GenBank accession no. ABD92880). The main extracellular protease MCP-01 was a cold-adapted protease which was thermolabile and susceptible to autolysis (Chen et al., 2002, 2003a, b). Moreover, strain SM9913 secreted large quantities of EPSs. In this study, the EPS secreted by strain SM9913 was purified and its structure was characterized. On the basis of the results, some ecological roles provided by the EPS are suggested that are relevant for adaptation to the deep-sea ecosystem.

\section{METHODS}

EPS production of strain SM9913 at different temperatures. In order to study the effect of temperature on EPS production, Pseudoalteromonas sp. strain SM9913 was cultured at $10^{\circ} \mathrm{C}, 20^{\circ} \mathrm{C}$ and $30^{\circ} \mathrm{C}$ using the method previously described (Chen et al., 2003a). The content of the EPSs in the culture supernanant was measured every $12 \mathrm{~h}$ by the phenol/ $\mathrm{H}_{2} \mathrm{SO}_{4}$ method (Dubois et al., 1956) after the culture was centrifuged at $10000 \mathrm{~g}$ for $12 \mathrm{~min}$ at $25^{\circ} \mathrm{C}$ (Eppendorf centrifuge 5804R). T-dextrans of different molecular masses (T-10, T-40, T-70, T-500 and T-2000, from Amersham Pharmacia Biotech) were used as standards.

Isolation and purification of the EPS. The exopolymer was precipitated from the supernatant of the culture by addition of cold absolute ethanol $(1: 1)$. Then, it was centrifuged at $10000 \mathrm{~g}$ for $10 \mathrm{~min}$ at $25^{\circ} \mathrm{C}$. The precipitate was dissolved in distilled water and decoloured with $5 \%(\mathrm{w} / \mathrm{v})$ activated charcoal. After removal of proteins from the exopolymer solution by the Sevag method (Staub, 1965), the crude EPS was obtained. The crude EPS was purified through gel-filtration chromatography, which was eluted with $0.1 \mathrm{M}$ $\mathrm{NaCl}$ aqueous solution through a column $(100 \times 1.6 \mathrm{~cm})$ of Sephadex G-100 at a flow rate of $12 \mathrm{ml} \mathrm{h}^{-1}$. The EPS fraction was collected and further purified through anion-exchange chromatography on a DEAE-Sepharose Fast Flow column, which was eluted with a linear gradient of 0 to $1 \mathrm{M} \mathrm{NaCl}$ aqueous solution at a flow rate of $60 \mathrm{ml} \mathrm{h}^{-1}$. The EPS fraction was collected. During these processes, the polysaccharide content was assayed by the phenol $/ \mathrm{H}_{2} \mathrm{SO}_{4}$ method and protein content was monitored by ultraviolet absorption spectroscopic analysis (Jasco). After dialysis against distilled water, concentration and lyophilization, the EPS was obtained.

The EPS obtained from chromatographic purification was further analysed on a Shimadzu analytical HPLC system with a Shimadzu autoinjector using a Waters Ultrahydrogel Linear column $(7.8 \times 300 \mathrm{~mm})$. All samples were prepared as $1 \%(\mathrm{w} / \mathrm{v})$ aqueous solutions and $20 \mu \mathrm{l}$ of sample solution was injected in each run process for $40 \mathrm{~min}$. Analytical liquid chromatography was performed in redistilled water at a flow rate of $0.4 \mathrm{ml} \mathrm{min}-1$ at $35^{\circ} \mathrm{C}$. The sample was detected with a Shimadzu refractive index detector. Preliminary calibration of the column was conducted with different T-dextrans as standards. The molecular mass of the EPS was analysed by the same HPLC system with T-dextrans of different molecular masses as standards. Chromatographic data were generated and processed with Shimadzu Class-VP software.

\section{Structural characterization of the EPS}

Constituent and methylation analysis of the EPS. For glycosyl linkage analysis, the EPS sample was permethylated, depolymerized, reduced and acetylated. The resultant partially methylated alditol acetates (PMAAs) were analysed by gas chromatography-mass spectrometry (GC-MS) as described by York et al. (1985). Initially, an aliquot of EPS sample was permethylated by the method of Ciucanu \& Derek (1984), treating with sodium hydroxide and methyl iodide in dry DMSO. The permethylation was repeated twice to ensure the complete methylation of the exopolymer. Following sample workup, the permethylated material was hydrolysed using $2.0 \mathrm{M}$ trifluoroacetic acid $\left(2 \mathrm{~h}\right.$ in a sealed tube at $\left.121^{\circ} \mathrm{C}\right)$, reduced with $\mathrm{NaBD}_{4}$, and acetylated using acetic anhydride/trifluoroacetic acid. The resulting PMAAs were analysed on a Hewlett Packard 5890 GC interfaced to a 5970 mass selective detector (MSD, electron impact ionization mode), and separation was performed on a $30 \mathrm{~m}$ Supelco 2330 bonded-phase fused-silica capillary column.

NMR spectral studies of the EPS. The EPS sample was treated with $\mathrm{D}_{2} \mathrm{O}$ to ensure the completion of the deuterium exchange before NMR analysis, dissolving the EPS solid (approx. $15 \mathrm{mg}$ ) in $\mathrm{D}_{2} \mathrm{O}(99.9 \%, 1.0 \mathrm{ml})$ at room temperature. After vortexing for 5 min at room temperature, the solution was frozen at $-70{ }^{\circ} \mathrm{C}$ and lyophilized to dry. This procedure was performed three times, and the EPS solid obtained was dissolved in $\mathrm{D}_{2} \mathrm{O}(99.9 \%, 0.5 \mathrm{ml})$, then transferred into an NMR tube. The solution obtained was cloudy. However, the precipitate could be removed by centrifuging at $6000 \mathrm{~g}$. The ${ }^{1} \mathrm{H}$ NMR spectrum of the cloudy solution was identical to that of the clear solution after centrifugation. The NMR spectra $\left[{ }^{1} \mathrm{H}\right.$ NMR, ${ }^{13} \mathrm{C}$ NMR, ${ }^{1} \mathrm{H}^{1}-\mathrm{H}^{1}$ correlation spectroscopy $\left(\mathrm{H}-{ }^{1} \mathrm{H}\right.$ COSY), heteronuclear single quantum correlation (HSQC)] were recorded on a $500 \mathrm{MHz}$ (DRX-500) Bruker NMR spectrometer.

\section{Analysis of the ecological role of the EPS}

Effect of the EPS on the thermostability and autolysis (selfdigestion) of the cold-adapted protease MCP-01. Purification and activity assay of cold-adapted protease MCP-01 from strain SM9913 were all done using the method previously described (Chen et al., 2003a). To study the effect of the EPS on MCP-01 thermostability, the protease solution with and without $1 \%(\mathrm{w} / \mathrm{v})$ the EPS was incubated at $40^{\circ} \mathrm{C}$ for $150 \mathrm{~min}$, and the residual protease activity was determined at intervals. The determination of MCP-01 autolysis at $4{ }^{\circ} \mathrm{C}$ and $40{ }^{\circ} \mathrm{C}$ was performed using capillary electrophoresis according to previously published procedures (Chen et al., 2003b). To study the effect of the EPS on MCP-01 autolysis, the protease 
solution with and without $1 \%(\mathrm{w} / \mathrm{v})$ EPS was incubated at $40{ }^{\circ} \mathrm{C}$ and the autolysis process of the samples was monitored by capillary electrophoresis.

Analysis of metal-binding property of EPS. Metal adsorption of the EPS from strain SM9913 was carried out by Salehizadeh's method (Salehizadeh \& Shojaosadati, 2003). In this experiment, $0.02 \%(\mathrm{w} / \mathrm{v})$ EPS and $2.0 \mathrm{mM}$ solution of each metallic ion (copper, magnesium, cobalt, manganese, iron, zinc and chromium) were used.

Flocculation analysis of the EPS. Kaolin was used to evaluate the flocculating ability of the EPS from strain SM9913 by the method of Anuradha \& Bajpai (2005). The mixture of $0.5 \%$ (w/v) kaolin, $0.05 \%(\mathrm{w} / \mathrm{v}) \mathrm{CaCl}_{2}$ and $0.001 \%(\mathrm{w} / \mathrm{v})$ EPS was vibrated in a table rotary shaker at 200 r.p.m. for $5 \mathrm{~min}$ and then equilibrated for $10 \mathrm{~min}$ at room temperature. The same sample without the EPS was used as a standard.

\section{RESULTS}

\section{Effect of temperature on the production of the EPS secreted by strain SM9913}

When strain SM9913 was cultured at $10^{\circ} \mathrm{C}, 20^{\circ} \mathrm{C}$ or $30^{\circ} \mathrm{C}$, after a short period of decrease, the sugar amount in the culture media continuously increased to a peak at $40-60 \mathrm{~h}$ and then declined. This indicated that the carbohydrate in the culture medium was utilized by strain SM9913 for growth at the beginning, and then strain SM9913 started to continuously secrete EPS. The yield of EPS increased as the temperature decreased in the tested range, indicating that the EPS production of strain SM9913 had cold-adaptation (see supplementary data, Part II, Fig. S1, available with the online version of this paper). Under optimal growth conditions $\left(15^{\circ} \mathrm{C}, 52 \mathrm{~h}\right)$, the yield of EPS reached $5.25 \mathrm{~g} \mathrm{l}^{-1}$ (dry weight), which was higher than that reported for the EPSs produced by other psychrotolerant microorganisms (Mancuso Nichols et al., 2005a).

\section{Isolation and purification of the EPS}

Two EPS peaks were eluted from the gel-filtration chromatographic column of Sephadex G-100. The first fraction was collected and further purified by anionexchange chromatography on a DEAE-Sepharose Fast Flow column (the latter was not collected because of limited contents). Homogeneity of the EPS purified by chromatography was analysed on the Shimadzu analytical HPLC system. Only one symmetrical acute peak was detected (see supplementary data, Part II, Fig. S2), which indicated that this EPS consisted of a single homogeneous component and could be used for structure analysis. The molecular mass of the EPS analysed by the same HPLC system was $4 \times 10^{4} \mathrm{Da}$.

\section{Structural characterization of the EPS}

Methylation analysis and glycosyl linkage analysis of the EPS. Glycosyl composition analysis of the EPS was initially performed and the results showed that it consisted mainly of glucose, with arabinose, xylose and a minor peak for mannose. It did not contain any aminoresidues. Linkage analysis of the EPS sample showed that it contained mainly 6-linked glucopyranosyl (6-Glc). Other linkages were terminal glucose, terminal arabinose and some minor peaks for terminal galactopyranosyl (t-Gal), 4linked glucopyranosyl (4-Glc), 4-linked xylofuranosyl (4Xyl-f) and 3,6-linked glucopyranosyl (3,6-Glc). These results showed that the main composition of the EPS was 6-Glc (61.8\%). Other components included terminal arabinofuranosyl (t-Ara f, $11.0 \%$ ) and terminal glucopyranosyl (t-Glc, $11.2 \%)$ together with a small amount of $\mathrm{t}$-Gal (3.1\%), 4-Xyl (f, 3.9\%), 4-Glc (5.0\%) and 3,6-Glc (4.0\%). These results confirmed the results from the latter NMR analysis, and also provided the linkage between the repeating sugar units as an $\alpha-(1 \rightarrow 6)$ linkage.

NMR analysis of the EPS. The ${ }^{1} \mathrm{H}$ NMR spectrum was first recorded at room temperature in $\mathrm{D}_{2} \mathrm{O}$, and only one anomeric proton signal was observed at 4.94 p.p.m. $(J=3.4 \mathrm{~Hz})$ (see supplementary data, Part II, Fig. S3). In order to avoid the overlap with $\mathrm{H}_{2} \mathrm{O}$ peak at 4.70 p.p.m., the ${ }^{1} \mathrm{H}$ NMR spectrum was also collected at different temperatures $\left(40^{\circ} \mathrm{C}\right.$ and $\left.60^{\circ} \mathrm{C}\right)$. The results indicated that the polysaccharide only presents one anomeric proton signal. From the coupling constant, the configuration of the sugar unit is $\alpha$-anomer $\left(J_{\mathrm{Heq}-\mathrm{Hax}}=3.4 \mathrm{~Hz}\right)$. The strong singlet at 2.19 p.p.m. implied the presence of an acetyl group $\left(-\mathrm{COCH}_{3}\right)$. The triplet at 1.14 p.p.m. $(J=7.1 \mathrm{~Hz})$ belongs to the $\mathrm{CH}_{3}$ in an ethoxyl group $\left(-\mathrm{OCH}_{2} \mathrm{CH}_{3}\right)$. The integration of the ${ }^{1} \mathrm{H}$ NMR spectrum indicated that the ratio between the sugar units, the acetyl group and the ethoxyl group is close to $4: 5: 1$. The rest of the signals at 4.0 p.p.m. to 3.4 p.p.m. belong to the protons on the sugar skeleton. The coupling patterns between these signals are hard to identify by $1 \mathrm{D}$ NMR. ${ }^{1} \mathrm{H}-{ }^{1} \mathrm{H}$ COSY (phase sensitive) was employed to resolve the coupling pattern and the coupling constants (results summarized in supplementary data, Part II, Table S1). The coupling pattern and the coupling constant obtained from the phase-sensitive ${ }^{1} \mathrm{H}_{-}{ }^{1} \mathrm{H}$ COSY, together with the chemical shift from the ${ }^{1} \mathrm{H}$ NMR spectra, showed that no amino group was present on the sugar skeleton (see supplementary data, Part II, Fig. S5). The coupling pattern and coupling constants strongly suggested that the repeating sugar unit has an $\alpha$-glucose skeleton. The ${ }^{13} \mathrm{C}$ NMR spectrum was recorded at room temperature in $\mathrm{D}_{2} \mathrm{O}$ (see supplementary data, Part II, Fig. S4). The signal at 215.45 p.p.m. indicated the carbonyl group of the acetyl functional group. The most intensive peak at 30.27 p.p.m. was assigned to the methyl group in the acetyl group. The peaks at 66.01 and 14.12 p.p.m. confirmed the ethoxyl group. Only one peak was observed in the anomeric region (97.75 p.p.m.), which also confirmed one set of repeating sugar units. The peaks at $73.43,71.43,70.21$, $69.57,65.58$ p.p.m. were assigned to the carbons on the sugar skeleton. The assignment of these carbon signals was facilitated by the HSQC spectrum (see supplementary data, Part II, Fig. S6; the final assignment of the ${ }^{13} \mathrm{C}$ 
signals is listed in supplementary data, Part II, Table S1). The down-field chemical shift of C3 indicated the attachment of the acetyl group at this position.

HRMS analysis of the EPS. The final assignment of the HRMS analysis is listed in supplementary data, Part II, Table S2. The observed $\left[\mathrm{M}+\mathrm{Na}^{+}\right]$is $927.2395(100.00 \%)$; $\left[\mathrm{M}+1+\mathrm{Na}^{+}\right]$is $928.2424(36.44 \%) ;\left[\mathrm{M}+2+\mathrm{Na}^{+}\right]$is 929.2421 (12.45\%) (supplementary data, Part II, Fig. S7). This result associated with the molecular formula $\mathrm{C}_{36} \mathrm{H}_{56} \mathrm{O}_{26} \mathrm{Na}^{+}$, which was consistent with the result obtained from the NMR analysis. The EPS contained four $\alpha$-glucose units, five acetyl groups and one ethoxyl group.

Based on the data obtained and the analysis above, this EPS was structurally characterized as a linear arrangement of $\alpha$ $(1,6) \rightarrow$ Glc and a high degree of acetylation. The repeating unit of the EPS was established as $\rightarrow 6)$-[3,6-O-acetyl]- $\alpha-\mathrm{D}-$ Glcp- $(1 \rightarrow 6)-[3-O$-acetyl]- $\alpha$-D-Glcp- $(1 \rightarrow 6)-[3-O$-acetyl]- $\alpha$ D-Glcp- $(1 \rightarrow 6)-[3-O$-acetyl]- $\alpha$-D-Glcp- $(1 \rightarrow$, and the structure of the EPS is shown in Fig. 1.

\section{Ecological role of the EPS from strain SM9913}

Effect of the EPS on the thermostability and autolysis of the cold-adapted protease MCP-01. Cold-adapted protease MCP-01, the main protease secreted by strain SM9913, was thermolabile and susceptible to autolysis (Chen et al., 2002, 2003b). Our previous study showed that autolysis of the purified protease MCP-01 was the main reason for its thermolability (Chen et al., 2003b). Here, protease MCP-01 was purified and the effect of the EPS secreted by strain SM9913 on the thermostability and autolysis of the protease was studied. The results showed that the EPS obviously enhanced the thermostability of protease MCP- 01 at $40{ }^{\circ} \mathrm{C}$. In the presence of EPS $(1 \%$, $\mathrm{w} / \mathrm{v})$, the protease activity of MCP-01 showed no evident change after $150 \mathrm{~min}$ incubation. In contrast, the protease activity in the absence of EPS was quickly lost, with $90 \%$ of the activity lost after $135 \mathrm{~min}$ incubation at $40{ }^{\circ} \mathrm{C}$ (Fig. 2). The autolysis process of protease MCP- 01 at $4{ }^{\circ} \mathrm{C}$ and $40{ }^{\circ} \mathrm{C}$ was monitored by capillary electrophoresis. Protease MCP- 01 autolysed slowly at $4{ }^{\circ} \mathrm{C} ; 57.3 \%$ of the

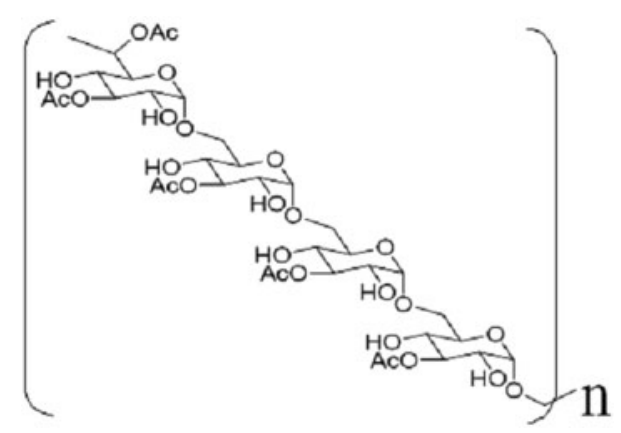

Fig. 1. Structure of the preponderant repeating units of the EPS from the deep-sea psychrotolerant strain SM9913.

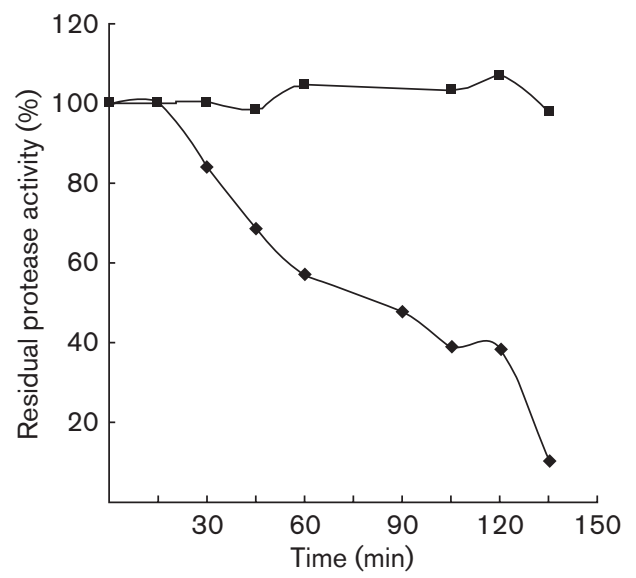

Fig. 2. Effect of the EPS from strain SM9913 on the activity of the cold-adapted protease MCP-01 secreted by the same strain. $\mathbf{\square}, \mathrm{MCP}-01$ with the EPS $(1 \%, \mathrm{w} / \mathrm{v}) ;$ out the EPS. The experiment was repeated three times; means of the three replicates are plotted.

protease had autolysed after incubation for $55 \mathrm{~h}$. At $40^{\circ} \mathrm{C}$, protease MCP-01 autolysed rapidly and the peak of MCP01 disappeared in $30 \mathrm{~min}$. But when $1 \%$ (w/v) EPS was added into the MCP-01 solution, the peak of MCP-01 showed no evident change during 50 min incubation at $40^{\circ} \mathrm{C}$ (see supplementary data, Part II, Fig. S8), indicating that the EPS prevented the autolysis of protease MCP-01 at $40^{\circ} \mathrm{C}$; this could be the reason why the EPS enhanced the thermostability of protease MCP-01.

Metal-binding property of the EPS. The metal-binding property of the EPS was studied and the adsorption percentage values $(Q)$ of each metal tested were calculated. The results showed that $\mathrm{Fe}^{2+}(85.00 \%), \mathrm{Zn}^{2+}(58.15 \%)$, $\mathrm{Cu}^{2+}(52.77 \%)$ and $\mathrm{Co}^{2+}(48.88 \%)$ were easily adsorbed by the EPS, while $\mathrm{Mg}^{2+}(30.69 \%)$ and $\mathrm{Mn}^{2+}(25.67 \%)$ were less adsorbed by the EPS. Of the metals tested, $\mathrm{Cr}^{6+}$ showed the lowest adsorption to the EPS (5.15\%). These results indicated that the EPS might be helpful for strain SM9913 to enrich metal ions in the nutrition-scant deep-sea environment.

Flocculation analysis of the EPS. The flocculation experiment showed that the EPS could make colloidal and suspended particles in solution conglomerate (see supplementary data, Part II, Fig. S9), suggesting that the EPS was a very good flocculating agent and had a good adsorptive effect. Therefore, it might play an important role for strain SM9913 in enriching nutrient particles in the deep-sea environment.

\section{DISCUSSION}

Many EPSs secreted by marine bacteria have been reported. Although EPSs from different strains may be different in 
yield, chemical composition, structure and physical properties, they have some common characteristics. Most EPSs produced by marine bacteria are heteropolysaccharides consisting of three or four different monosaccharides arranged in groups of ten or fewer to form repeating units (Decho, 1990). The monosaccharides may be pentoses, hexoses, amino sugars or uronic acids. EPSs from marine bacteria usually possess hydroxyl and carboxyl groups, which confer a net negative charge and acidic properties to the EPSs. Up to $20-50 \%$ of these EPSs may be uronic acids. Most EPSs are linear overall and of varying lengths, with a mean molecular mass of $1 \times 10^{5}$ to $3 \times 10^{5} \mathrm{Da}$. Branches of one or more monosaccharides are often attached at regular intervals. Organic or inorganic (sulfate, phosphate) substituents may also be present (Mancuso Nichols et al., 2005b). In recent years, some EPSs secreted by marine bacteria from deep-sea hydrothermal vents have been reported. Most of them are acidic polysaccharides with uronic acid content from $10 \%$ to $40 \%$ and high molecular mass up to $10^{6} \mathrm{~g} \mathrm{~mol}^{-1}$ (Guezennec, 2002).

In this study, the EPS secreted by strain SM9913, a deep-sea psychrotolerant bacterium isolated from sediment at $1855 \mathrm{~m}$ depth, was purified and its structure was elucidated. To our knowledge this is the first report on the EPS from a deep-sea psychrotolerant bacterium. Its structure was quite different from that of the EPSs secreted by marine bacteria from hydrothermal vents and other areas, including Antarctic Pseudoalteromonas strains (Mancuso Nichols et al., 2005a; Guezennec, 2002). The EPS from strain SM9913 was an acetyl-rich EPS with a molecular mass of $4 \times 10^{4} \mathrm{Da}$, which was smaller than most of the EPSs secreted by the bacteria from deep-sea hydrothermal vents. Unlike most of the EPSs secreted by other marine bacteria, The EPS from strain SM9913 did not possess uronic acid. Its structure was a linear arrangement of $\alpha-(1,6) \rightarrow$ Glc with a high degree of acetylation. Acetyl groups have been found in other marine EPSs such as the EPS produced by psychrotolerant strains CAM025 and CAM036 from Antarctic water and sea ice (Mancuso Nichols et al., 2004, 2005). But an EPS with so high a degree of acetylation from a marine bacterium is an unusual finding. In contrast, the EPSs from deep-sea hydrothermal vent bacteria have no or few acetyl groups (Guezennec, 2002).

The ecological roles of EPSs from marine bacteria have been reviewed (Mancuso Nichols et al., 2005b). In the marine environment, bacterial EPSs are essential in the production of aggregates, adhesion to surfaces and other organisms, biofilm formation and sequestering of nutrients, and thus provide protection and ecosystem stability (Mancuso Nichols et al., 2005b). Although the structures of the EPSs from several deep-sea meso- or thermophilic bacteria have been elucidated (Raguenes et al., 1996, 1997, 2003; Rougeaux et al., 1999; Bowman, 1998; Muldoon et al., 2003), there is little information on the ecological function of the EPSs from the deep-sea bacteria. In this study, besides the structural elucidation of the EPS from strain SM9913, several experiments were done to investigate its ecological role in the cold deep-sea environment.

Most of the EPSs from marine bacteria are acidic extrapolysaccharides with net negative charge, which gives the molecule a 'sticky' quality (Mancuso Nichols et al., 2005b). Some of them have been proved to have metalbinding capacity (Loaec et al., 1997). The metal-binding properties of the EPSs produced by the Antarctic marine isolates were suggested by the authors as one potential ecological role for these polymers (Mancuso Nichols et al., 2005a). The EPS from strain SM9913 included high levels of acetyl groups, which were polyanionic and therefore sticky for cations. Our data showed that this EPS was able to bind a range of metal cations, such as $\mathrm{Fe}^{2+}, \mathrm{Zn}^{2+}, \mathrm{Cu}^{2+}$ and $\mathrm{Co}^{2+}$, indicating that it might function in concentrating helpful metal ions to the surface of the strain in the microenvironment around the cell.

Recently, the genome sequence of the deep-sea gammaproteobacterium I. loihiensis was reported and it was suggested that this species relies primarily on amino acids, rather than on carbohydrates, for carbon and energy (Hou et al., 2004). EPSs secreted by this species may function in colonizing proteinaceous particles in the surrounding environment (Hou et al., 2004). The flocculation experiment on the EPS secreted by strain SM9913 showed that it was a very good flocculating agent and had a high ability to adhere to suspended articles in the surrounding environment, indicating that it could adhere to proteinaceous particles available in the deep-sea environment when it was secreted by strain SM9913.

Cold-adapted protease MCP-01, which was thermolabile and susceptible to autolysis, was the main protease secreted by strain SM9913. So it is very important for the strain's ability to utilize proteins in the surrounding environment. Our results showed that the EPS secreted by strain SM9913 could stabilize protease MCP-01 and effectively prevent its autolysis in vitro. This is believed to be the first report that EPS secreted by a marine bacterium has a stabilizing function on the proteases secreted by the same strain. Therefore, in the cold deep-sea environment, the EPS from strain SM9913 might play a role in stabilizing the proteases from the same strain in situ. It could also concentrate the proteases secreted by this strain by preventing protease diffusion. So the proteinaceous particles concentrated by the EPS could be effectively digested by the proteases into amino acids and oligopeptides and they, together with the concentrated metal ions, could be adsorbed by the strain as a source for growth and energy. Therefore, the EPS secreted by strain SM9913 may play important roles in the survival of this strain in the deep-sea nutrient-scarce environment.

Based on these experimental results and other studies, a schematic diagram of the lifestyle of deep-sea psychrotolerant strain SM9913 is proposed in Fig. 3, revealing an integrated mechanism of metabolic adaptation of this strain 


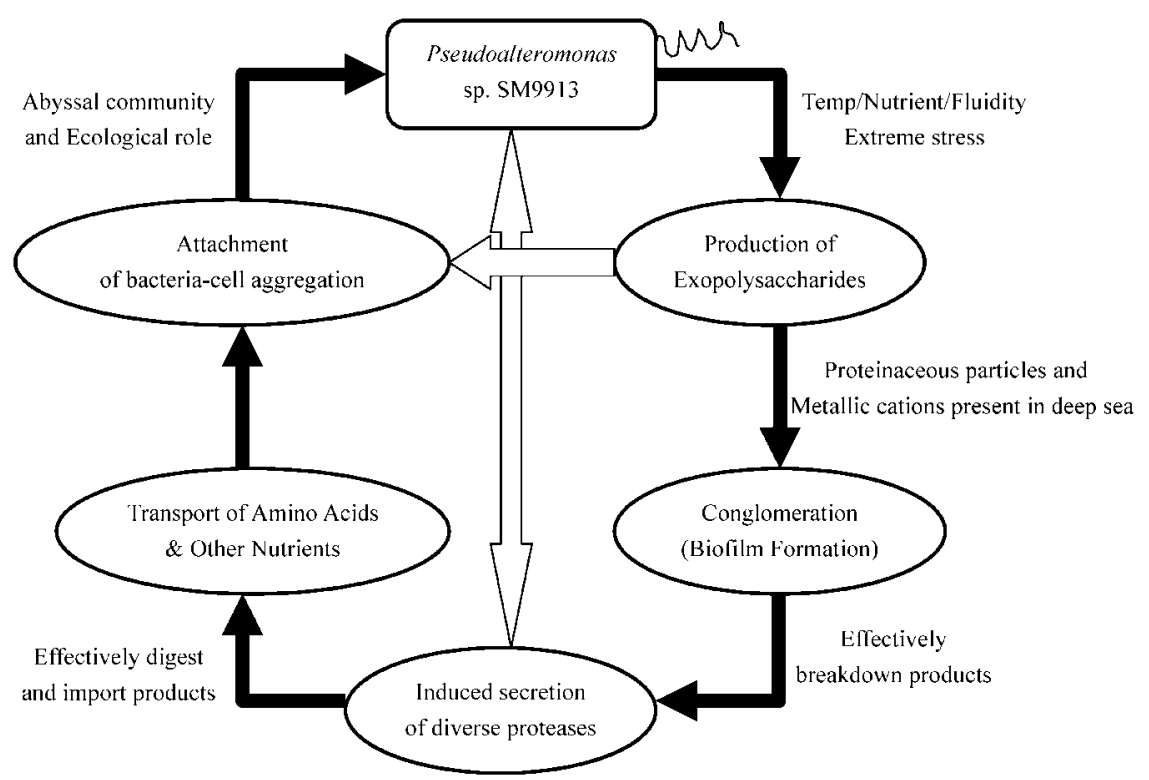

Fig. 3. Schematic diagram of lifestyle of the deep-sea psychrotolerant strain SM9913 inferred from experimental analysis. to the low temperature, organic and inorganic nutrientscarce, constantly changing deep-sea environment.

\section{ACKNOWLEDGEMENTS}

This work was supported by the Hi-Tech Research and Development Program of China (2006AA06Z326, 2006AA09Z414), the Science and Technology R\&D Program of Shandong Province of China (2005JJ3205108), the Natural Science Foundation of Shandong Province of China (Z2004D02), and the Foundation for Young Excellent Scientists in Shandong Province (2006BS02002).

\section{REFERENCES}

Anuradha, M. \& Bajpai, M. (2005). Flocculation behaviour of model textile wastewater treated with a food grade polysaccharide. J Hazardous Materials B118, 213-217.

Bowman, J. P. (1998). Pseudoalteromonas prydzensis sp. nov., a psychrotrophic, halotolerant bacterium from Antarctic sea ice. Int J Syst Bacteriol 3, 1037-1041.

Cambon-Bonavita, M. A., Raguenes, G., Jean, J., Vincent, P. \& Guezennec, J. (2002). A novel polymer produced by a bacterium isolated from a deep-sea hydrothermal vent polychaete annelid. J Appl Microbiol 93, 310-315.

Chen, X. L., Sun, C. Y., Zhang, Y. Z. \& Gao, P. J. (2002). Effects of different buffers on the thermostability and autolysis of a coldadapted protease MCP-01. J Protein Chem 21, 523-527.

Chen, X. L., Zhang, Y. Z., Gao, P. J. \& Luan, X. W. (2003a). Two different proteases produced by a deep-sea psychrotrophic strain Pseudoaltermonas sp. SM9913. Mar Biol 143, 989-994.

Chen, X. L., Sun, C. Y., Zhang, Y. Z. \& Gao, P. J. (2003b). Rapid monitoring of autolysis process of proteases by capillary electrophoresis. Biotechnol Lett 25, 1763-1767.

Ciucanu, I. \& Derek, F. (1984). A simple and rapid method for the permethylation of carbohydrates. Carbohydr Res 131, 209-217.

Colliec-Jouault, S., Zanchetta, P., Helley, D., Ratiskol, J., Sinquin, C., Fischer, A. M. \& Guezennec, J. (2004). Microbial polysaccharides of marine origin and their potential in human therapeutics. Pathol Biol 52, 127-130.

Decho, A. W. (1990). Microbial exopolymer secretions in ocean environments: their role(s) in food webs and marine processes. In Oceanography and Marine Biology: an Annual Review, pp. 73-153. Edited by M. Barnes. Aberdeen, UK: Aberdeen University Press.

Dubois, M., Gilles, K. A., Hamilton, J. K., Rebers, P. A. \& Smith, F. (1956). Colorimetric method for determination of sugars and related substances. Anal Chem 28, 350-356.

Guezennec, J. (2002). Deep-sea hydrothermal vents: a new source of innovative bacterial exopolysaccharides of biotechnological interest? $J$ Ind Microbiol Biotechnol 29, 204-208.

Guezennec, J. (2003). From extreme environments to biologically active exopolysaccharides. Commun Agric Appl Biol Sci 68, 227-234.

Hou, S. B., Jimmy, H. S., Lee, K. S., Freitas, T. A., Belisle, C., Kawarabayasi, Y., Donachie, S. P., Pikina, A., Galperin, M. Y. \& other authors (2004). Genome sequence of the deep-sea $\gamma$ proteobacterium Idiomarina ioihiensis reveals amino acid fermentation as a source of carbon and energy. Proc Natl Acad Sci U S A 101, 18036-18041.

Kirschner, K. N. \& Woods, R. J. (2001). Solvent interactions determine carbohydrate conformation. Proc Natl Acad Sci U S A 98, 10541-10545.

Loaec, M., Olier, R. \& Guezennec, J. (1997). Uptake of lead, cadmium and zinc by a novel bacterial exopolysaccharide. Water Res 31, 1171-1179.

Mancuso Nichols, C. A., Garon, S., Bowman, J. P., Raguenes, G. \& Guezennec, J. (2004). Production of exopolysaccharides by Antarctic marine bacterial isolates. J Appl Microbiol 96, 1057-1066.

Mancuso Nichols, C. A., Bowman, J. P. \& Guezennec, J. (2005a). Effects of incubation temperature on growth and production of exopolysaccharides by an Antarctic sea ice bacterium grown in batch culture. Appl Environ Microbiol 71, 3519-3523.

Mancuso Nichols, C. A., Guezennec, J. \& Bowman, J. P. (2005b). Bacterial exopolysaccharides from extreme marine environments with special consideration of the southern ocean, sea ice, and deepsea hydrothermal vents: a review. Marine Biotechnol 7, 253-271.

Muldoon, J., Perepelov, A. V., Shashkov, A. S., Nazarenko, E. L., Zubkov, V. A., Gorshkova, R. P., Ivanova, E. P., Gorshkova, N. M., 
Knirel, Y. A. \& Savage, A. V. (2003). Structure of an acidic polysaccharide from the marine bacterium Pseudoalteromonas flavipulchra NCIMB 2033. Carbohydr Res 338, 459-462.

Rademacher, T. W., Parekh, R. B. \& Dwek, R. A. (1988). Glycobiology. Annu Rev Biochem 57, 785-838.

Raguenes, G., Pignet, P., Gauthier, G., Peres, A., Christen, R., Rougeaux, H., Barbier, G. \& Guezennec, J. (1996). Description of a new polymer-secreting bacterium from a deep-sea hydrothermal vent, Alteromonas macleodii subsp. fijiensis, and preliminary characterization of the polymer. Appl Environ Microbiol 62, 67-73.

Raguenes, G., Christen, R., Guezennec, J., Pignet, P. \& Barbier, G. (1997). Vibrio diabolicus sp. nov., a new polysaccharidesecreting organism isolated from a deep-sea hydrothermal vent polychaete annelid, Alvinella pompejana. Int J Syst Bacteriol 47, 989-995.

Raguenes, G., Cambon-Bonavita, M. A., Lohier, J. F., Boisset, C. \& Guezennec, J. (2003). A novel, highly viscous polysaccharide excreted by an Alteromonas isolated from a deep-sea hydrothermal vent shrimp. Curr Microbiol 46, 448-452.
Rougeaux, H., Guezennec, J., Carlson, R. W., Kervarec, N., Pichon, R. \& Talaga, P. (1999a). Structural determination of the exopolysaccharide of Pseudoalteromonas strain HYD 721 isolated from a deep-sea hydrothermal vent. Carbohydr Res 315, 273-285.

Rougeaux, H., Kervarec, N., Pichon, R. \& Guezennec, J. (1999b). Structure of the exopolysaccharide of Vibrio diabolicus isolated from a deep-sea hydrothermal vent. Carbohydr Res 322, 40-45.

Salehizadeh, H. \& Shojaosadati, S. A. (2003). Removal of metal ions from aqueous solution by polysaccharide produced from Bacillus firmus. Water Res 37, 4231-4235.

Staley, J. T. \& Gosink, J. J. (1999). Poles apart: biodiversity and biogeography of sea ice bacteria. Annu Rev Microbiol 53, 189-215.

Staub, A. M. (1965). Removal of proteins: Sevag method. Methods Carbohydr Chem 5, 5-6.

York, W. S., Darvill, A. G., McNeil, M., Stevenson, T. T. \& Albersheim, P. (1985). Isolation and characterization of plant cell walls and cell wall components. Methods Enzymol 118, 3-40.

Edited by: H.-P. Klenk 